\title{
Effects of Recombinant Angiogenin on Collagen Fiber Formation and Angiogenesis in the Dermis of Wistar Rats
}

This article was published in the following Dove Press journal: Clinical, Cosmetic and Investigational Dermatology

\author{
Natalia $\vee$ Yurina $\mathbb{D}^{\prime}$ \\ Tatiana A Ageeva (iD ${ }^{2}$ \\ Aleksandr M Goryachkin (iD) ${ }^{2}$ \\ Nikolay A Varaksin ${ }^{3}$ \\ Tatiana G Ryabicheva ${ }^{3}$ \\ Alexandr A Ostanin (D) ${ }^{4}$ \\ Elena R Chernykh (D) ${ }^{4}$ \\ Alexander V Romashchenko (iD ${ }^{5}$ \\ Anastasia S Proskurina $\left(\mathbb{D}^{5}\right.$ \\ Sergey Bogachev $\mathbb{D}^{5}$ \\ Alexey $\vee$ Purtov $^{6}$ \\ 'Autonomous Non-Profit Organization \\ "Regional Center for High Medical \\ Technologies", Novosibirsk, Russia; \\ ${ }^{2}$ Novosibirsk State Medical University, \\ Novosibirsk, Russia; ${ }^{3} \mathrm{JSC}$ "Vector-Best", \\ Novosibirsk, Russia; ${ }^{4}$ Research Institute \\ of Fundamental and Clinical Immunology, \\ Novosibirsk, Russia; ${ }^{5}$ Institute of \\ Cytology and Genetics, Siberian Branch \\ of the Russian Academy of Sciences, \\ Novosibirsk, Russia; ' LLC “Angiopharm \\ Laboratory”, Novosibirsk, Russia
}

Correspondence: Sergey Bogachev

Email labmolbiol@mail.ru
Purpose: The purpose of this study was to assess the capability of recombinant angiogenin isolated from Pichia pastoris yeasts to stimulate regenerative processes in the dermis of experimental animals.

Patients and Methods: Wistar rats were administered with recombinant angiogenin intracutaneously. Morphological examination of the skin and the assessment of the proliferative activity of the epidermal cells were carried out. Additionally, cytokine production by human whole blood cells exposed to angiogenin was analyzed ex vivo.

Results: Administration of angiogenin stimulates collagen fiber formation and angiogenesis. This stimulation is tightly associated with an increase in the number of fibroblasts, an increased numerical density of dermal blood vessels and an increased density of collagen fibers; also, it activates the proliferation of basal cells. Angiogenin induces the production of MCP, IL- 8 , IL-6, IL-1 $\beta$, TNF- $\alpha$, IL-10, TGF- $\beta$, and VEGF by blood cells.

Conclusion: The results obtained indicate a broad spectrum of actions of recombinant angiogenin during regenerative processes in the basal layer of the dermis.

Keywords: intracutaneous injections, pathomorphological analysis, cytokines, regeneration

\section{Introduction}

Angiogenin, also known as secreted ribonuclease 5 (RNase 5), is a strong inducer of angiogenesis. It plays a key role in a variety of physiological and pathological processes, including reproductive cycles, embryonic and postnatal tissue development, the regeneration of damaged tissues and the hematopoietic system, neuroprotection, inflammation and tumorigenesis. ${ }^{1-4}$ Angiogenin is a polyfunctional protein presented in the blood, mother's milk, amniotic and cerebrospinal fluids. As other acute-phase proteins, angiogenin is actively synthesized in liver cells in stressful situations, allowing it to be considered as a protective homeostatic factor.

In contrast to other angiogenic factors, such as vascular endothelial growth factor (VEGF), placental growth factor (PlGF), hepatocyte growth factor (HGF), fibroblast growth factor (FGF) and epidermal growth factor (EGF), angiogenin exerts a ribonuclease enzymatic activity. ${ }^{5}$ The main targets of angiogenin are vascular endothelial cells, fibroblasts and smooth muscle cells. Angiogenesis initiation occurs upon the binding of angiogenin to actin located on the membranes of endothelial cells ${ }^{6,7}$ and consequent activation of the plasminogen activator, which, in turn, results in the formation of plasmin, which, in conjunction with a variety of 
activated matrix metalloproteinases, destroys laminin and fibronectin of the basal membrane. Destruction of the basal membrane and extracellular matrix is believed to be essential for the migration of endothelial cells during neovascularization. ${ }^{8}$

Activated endothelial cells express, on their cytoplasmic membrane, the specific angiogenin-binding receptor plexin-B2 (PLEXINB2), which mediates the induction of a variety of intracellular pathways (ERK1/2, PKB/Akt, SAPK/JNK), resulting in an increased production of ribosomal proteins essential for cell growth. ${ }^{9}$ Angiogenin also induces the synthesis of nitric oxide, a key biological regulator of the vascular tone. Moreover, angiogenin initiates the NF- $\mathrm{kB}$-mediated signaling and the Bcl-2-mediated antiapoptotic pathway. ${ }^{10-15}$

The main mechanism of angiogenin-mediated angiogenesis is associated with this polypeptide's capability of inducing ribosomal RNA transcription. After endocytic internalization, angiogenin undergoes nuclear translocation and accumulates in nucleoli, where it binds to DNA promoter regions by its specific nuclear localization sequence (NLS) and thus activates the transcription of ribosomal RNA, which is a key event in ribosome biogenesis, and, consequently, in the subsequent synthesis of a variety of proteins essential for the cell growth and survival, and for the formation of new vessels. ${ }^{2,5,13,16-21}$

The activity of angiogenin depends on its localization. In unstressed cells, angiogenin is mainly localized in the nucleus, while in the cytoplasm, angiogenin is inactive due to its binding to the placental inhibitor of ribonucleases RNH1. In stressed cells (unusual tissue localization, hypoxia, trophic imbalance, heat shock, oxidative stress), angiogenin undergoes cytoplasmic translocation, dissociates from RNH1 and accumulates in stress granules. Stress granules contain untranslated mRNAs, $40 \mathrm{~S}$ ribosome subunits, translation initiation factors, RNA-binding proteins and signaling molecules. Such a deposition and preservation of these components provide cell survival under stressful conditions. ${ }^{9,13,18,22,23}$

Specific hydrolysis of the transfer RNA anticodon loop by angiogenin results in the formation of small non-coding fragments 30-40 nucleotides in size designated as $5^{\prime}$ and $3^{\prime}$ tiRNA (tRNA-derived, stress-induced small RNAs). 5' tiRNAs (but not $3^{\prime}$ tiRNA) are strong inhibitors of protein synthesis, allowing cells to keep anabolism-derived energy for repairing lesions caused by stressful conditions. Angiogenin increases cell viability under stressful conditions by preventing apoptosome formation and caspase-3 activation due to binding of $5^{\prime}$ tiRNA and $3^{\prime}$ tiRNA to cytochrome C. ${ }^{1,23-29}$

At the final stage, proliferating, freely located endothelial cells form a new blood tube, which is further hardened with smooth muscle cells to form a new blood vessel. ${ }^{19}$ Perivascularly located fibroblasts also play a significant role in this process by producing specific proteins of the extracellular matrix (ECM) in response to stimulation with angiogenin. ECM proteins mediate interactions between fibroblasts and endothelial cells, facilitating the folding of the newly formed endothelium into the functional tube of a new vessel. ${ }^{30,31}$

In addition to its main function as an angiogenesis activator, angiogenin regulates the process of inflammation. The anti-inflammatory properties of angiogenin have been demonstrated in the models of IL-1 $\beta$ - or TNF- $\alpha$ induced inflammation. Moreover, angiogenin is known to suppress the degranulation of polymorphonuclear leukocytes, and so it participates in endogenous feed-back inhibition during the development of inflammatory reactions. ${ }^{11,32-37}$

The functional activity of angiogenin substantially determines the course and resolution of the wound healing process, both directly, by stimulating neovascularization, and indirectly, by activating fibroblasts and the factors they produced. ${ }^{3,4,38-40}$

In the current investigation, experiments demonstrating the effects of angiogenin on the basic parameters of the dermis as a barrier tissue protecting the organism from a variety of damaging factors have been carried out. The results obtained indicate that intracutaneous injections of angiogenin induce tissue-specific pathomorphological changes in the dermis, which plays an important role in regenerative processes. Additionally, cytokine production by human whole blood cells has been assayed ex vivo. These cells have been found to secrete both pro- and antiinflammatory cytokines.

\section{Materials and Methods}

\section{Angiogenin Preparation}

Recombinant angiogenin was provided by the manufacturing company LLC “Angiopharm Laboratory”, Novosibirsk. ${ }^{41}$

\section{Experimental Animals}

Experimental animals were provided by the Laboratory of Pharmacological Research, N.N. Vorozhtsov Novosibirsk Institute of Organic Chemistry, SB RAS. The research was 
performed on Wistar female rats provided by the vivarium of the Institute of Cytology and Genetics, SB RAS. Experimental animals were kept in separate plastic cages (5 animals per cage) with unlimited access to food and water, at $20-22^{\circ} \mathrm{C}$ under a $12: 12$ light/dark cycle. All experiments were performed in accordance with the protocols approved by the Animal Care and Use Committee of the Institute of Cytology and Genetics and the GLP rules.

\section{Administration of the Preparations}

Animals were injected either with $0.2 \mathrm{~mL}$ physiological saline solution or with angiogenin at doses of 0.4 or $0.8 \mu \mathrm{g}$ intracutaneously across an area of $10 \mathrm{~cm}^{2}(2.5 \mathrm{~cm} \times$ $4.0 \mathrm{~cm}$ ) once per week. Samples were taken after three $(\mathrm{n}=5$ in each group) or $\operatorname{six}(\mathrm{n}=5$ in each group) injections. A separate group of intact animals $(n=5)$ was sampled. The preparations were injected by multiple intracutaneous micro-injections with an interval of 3-4 $\mathrm{mm}$ (or less) between puncture sites, papules with a diameter of $1-2 \mathrm{~mm}$ and a volume of $0.01-0.02 \mathrm{~mL}$; the needle was injected at an angle of $45^{\circ}$ relative to the skin surface. The needle cut orientation was not taken into account.

\section{Morphological Examination of the Skin}

For morphological examination, strips of the skin from the area of injections were fixed in 10\% neutral formalin and subjected to standard processing on a Leica TP1020 histological complex, followed by embedding in paraffin blocks. A Leica RM2235 rotary microtome was used for preparing 3-4 $\mu \mathrm{m}$ sections, which were further stained with hematoxylin and eosin in a Leica ST5010 autostainer and stained for elastic fibers of connective tissue using the Weigert-van Gieson technique. Preparations were examined in transmitted light on a Leica DM2500 microscope. The thicknesses of the dermis (papillary and reticular layers) and the stratum corneum of the epidermis (without the cellular layer of the epidermis) were measured. The thickness of the dermis was measured at a $100 \times$ magnification using an eyepiece micrometer with a scale division of $0.01 \mathrm{~mm}$; the thickness of the epidermis was measured at a $400 \times$ magnification using an eyepiece micrometer with a scale division of $0.0025 \mathrm{~mm}$. In the dermis, the number of fibroblasts and blood vessels across the section surface was counted at a $630 \times$ magnification without immersion on the Leica DM2500 microscope using a 121-node morphometric grid.

\section{Measuring of the Density of Elastic and Collagen Fibers}

The density of collagen fibers was estimated in 25 fields of view at a $400 \times$ magnification using the 121-node morphometric grid on the Leica DM2500 microscope. The density of elastic fibers was estimated in 25 fields of view at a $1000 \times$ magnification using the 121 -node morphometric grid on the Leica DM2500 microscope. The density of elastic and collagen fibers was estimated using the following formula: $\mathrm{V}=\mathrm{x} / \mathrm{n}$, where $\mathrm{x}$ is the number of dots corresponding to a certain structural component and $n$ is the total number of dots counted. ${ }^{42}$

\section{Assessing the Proliferative Activity of the Epidermal Cells}

Immunohistochemical staining was performed using the standard protocol on Autostainer Link 48 (Dako), EnVision ${ }^{\mathrm{TM}}$ Flex+, Mouse, High pH, (Link) Code K8002 (Dako) and Monoclonal Mouse Anti-Human Ki-67 Antigen, Clone MIB1, Code M7240 antibodies (Dako). Preparations were examined in transmitted light on the Leica DM2500 microscope. Proliferative activity of the epidermal cells was estimated as the number of Ki-67-positive cells with a medium and an intense specific nuclear reaction per 100 epidermal cells in 10 fields of view (\%).

\section{Ex vivo Assessment of Cytokine Production by Human Whole Blood Cells}

The study was performed in accordance with the principles stated in the Declaration of Helsinki and was approved by the Ethic Committee of the Research Institute of Fundamental and Clinical Immunology. Peripheral blood samples were obtained from healthy donors. The participants provided written informed consent. To assess, in ex vivo settings, cytokine production by whole human blood cells, peripheral blood samples from three donors and angiogenin at concentrations of $0.01,0.1$ and $1.0 \mu \mathrm{g} / \mathrm{mL}$ were used. Blood samples were incubated with and without angiogenin for 24 hours at $37^{\circ} \mathrm{C}$ and cells were sedimented at $10,000 \mathrm{~g}$ for three minutes. The remaining supernatant was aliquoted, frozen and stored at $-40^{\circ} \mathrm{C}$ until assaying. The IL-2, IL-4, IL-6, IL-8, IL-10, IL-18, IL- $1 \beta$, TNF- $\alpha$, IFN- $\gamma$, VEGF and MCP-1 contents were determined by a solid-phase immunoassay using kits from "Vector-Best" (Russia); the G-CSF, GM-CSF, IL-17 and TGF- $\beta$ contents were determined using kits from R\&D Systems (United Kingdom). To quantify the effect of 
angiogenin on cytokine production, we used the "Influence index", which was calculated as the ratio of cytokine content in angiogenin-treated blood to the basal level of cytokine production by untreated blood.

\section{Statistical Data Processing}

During the statistical analysis, mean values with standard errors were calculated. The difference between the means was validated using the Student's $t$-test. Data were considered valid at $\mathrm{p}<0.05$. For statistical processing, Statistica 6.0 for Windows and MS Excel were used.

\section{Results}

\section{State of the Dermis After Exposure to Angiogenin}

To assess the effect of recombinant angiogenin on collagen fiber formation and angiogenesis, Wistar rats were administered with the preparation intracutaneously.

In intact animals, an epidermal strip was represented as a multilayer squamous keratinizing epithelium with up to three cellular layers identifiable (Figure 1). The dermis was represented as papillary and reticular layers without a definitive border between them. The papillary layer of the dermis was found directly under the epidermis and consisted of loose fibrous connective tissue. The connective tissue of the reticular layer of the dermis was represented by thin collagen and elastic fibers, skin appendages of a typical morphological texture and cells with a predominance of fibroblasts, histiocytes and lymphocytes. The number of skin appendages differed between samples. In all samples, superficial erosive injuries of the epidermis with small intraepidermal accumulations of neutrophils were detected.

In animals administered with saline, expansion of the stratum corneum was observed, the papillary and reticular layers of the dermis were represented by coarse, swollen collagen. The dermal edema, observed as the uncoupling of collagen fibers, was detected (Figure 1).

In animals treated with 0.4 and $0.8 \mu \mathrm{g}$ of angiogenin three times, the epidermis was expanded and represented by 4-6 layers of cells with a pronounced granular layer and moderate keratinization. In animals treated with $0.4 \mu \mathrm{g}$ of angiogenin three times, collagen fibers of connective tissue in the papillary and reticular layers of the dermis were thickened, swollen and oriented in one direction (Figure 1). A narrow stripe of newly formed collagen and several fibroblast aggregations were identifiable in the injection area.
In animals treated with 0.4 and $0.8 \mu \mathrm{g}$ of angiogenin six times, the thickness of the epidermis was accounted for by two to five cellular layers without acanthosis and with moderate keratinization. No neutrophil accumulations were observed. The granular layer consisted of up to two cellular layers.

Figure 2 shows the results of measuring the thicknesses of the dermis and stratum corneum (Figure 2A and B), the number of fibroblasts and blood vessels (Figure 2C and $\mathrm{D})$, and the density of dermal elastic and collagen fibers in the treated area (Figure 2E and F).

In animals treated with saline three times, increased thicknesses of the dermis and stratum corneum relative to the intact controls were observed (Figure $2 \mathrm{~A}$ and $\mathrm{B}$ ).

In animals treated with 0.4 or $0.8 \mu \mathrm{g}$ of angiogenin three times, a thickening of the dermis and stratum corneum relative to the intact controls were observed (Figure 2A and B). In these groups, a significant increase in the number of fibroblasts and the densities of dermal blood vessels and collagen fibers relative to the intact controls and animals treated with saline was detected (Figure 2C and D and F). No significant differences between the groups treated with 0.4 and $0.8 \mu \mathrm{g}$ of angiogenin were found.

In the animals treated with $0.4 \mu \mathrm{g}$ of angiogenin six times, the thickness of the stratum corneum was increased relative to that in the animals treated with $0.4 \mu \mathrm{g}$ of angiogenin three times (Figure 2B). The thicknesses of the dermis and stratum corneum, the number of vessels and the density of collagen fibers were significantly increased in them relative to those in the intact controls and animals treated with saline (Figure 2A and $\mathrm{B}$ and $\mathrm{D}$ and $\mathrm{F}$ ).

In the animals treated with $0.8 \mu \mathrm{g}$ of angiogenin six times, all the parameters monitored had the maximum values, which were definitely higher than those in the intact controls and animals treated with saline (Figure 2).

\section{Assessing the Proliferation of Epidermal Cells}

The proliferative index of basal cells of the epidermis (Ki67) following three- and six-time administration of $0.8 \mu \mathrm{g}$ of angiogenin was significantly higher relative to both the intact controls and the group receiving saline (Figure 3).

\section{Angiogenin Stimulates Cytokine Production by Human Whole Blood Cells} Angiogenin is produced by a variety of cell types and is involved in the paracrine regulation of multiple processes, including embryogenesis, perinatal development, the 


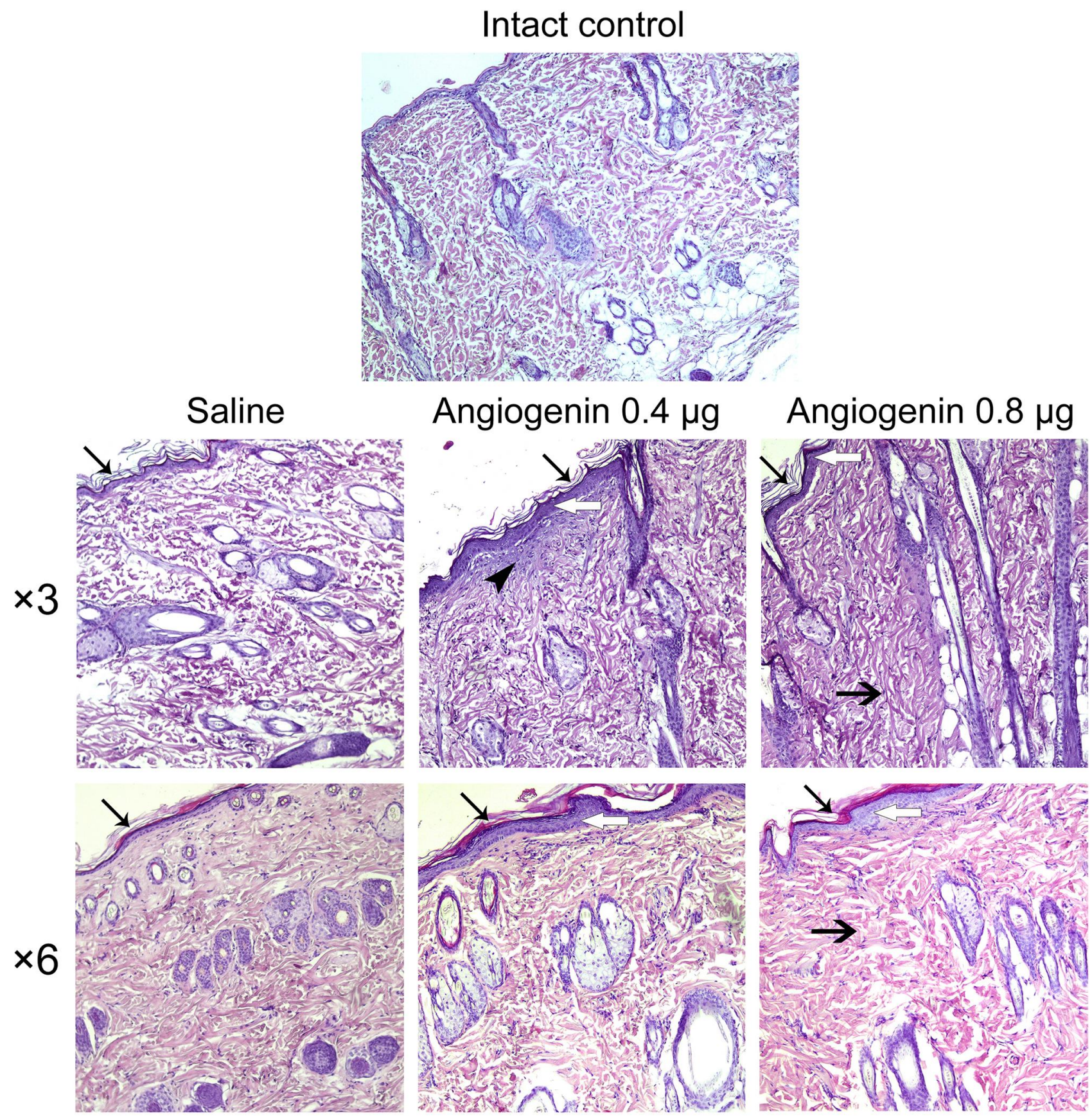

Figure I Skin from the back of the intact animal and animals after three and six injections of each saline, 0.4 and $0.8 \mu \mathrm{g}$ of angiogenin. $\longrightarrow$ Expansion of the stratum corneum, $\longrightarrow$ an increase in the number of epidermal layers, $\rightarrow$ thickened collagen fibers, the site of newly formed collagen with proliferating fibroblasts (the edge of the injection area). Hematoxylin/eosin staining, 100x magnification.

development of immune tolerance, and hematopoietic homeostasis. ${ }^{19}$ Thus, different types of cells are sensitive to angiogenin and can specifically respond to exposure. Intradermal administration of angiogenin results in a significant increase in its local concentration and consequent activation of blood cells in the microcirculatory/capillary bed of the dermis at the injection site. An increased cytokine production by a variety of cells located both in the endo- and perivascular space could be presumed as a manifestation of such activation.

To test this presumption, an ex vivo analysis of cytokine production by whole blood cells exposed to angiogenin was performed in a human model. The production of pro-inflammatory cytokines (TNF- $\alpha$, IL-1 $\beta$, IL-6, IFN- $\gamma$, IL-17, IL-18), anti-inflammatory cytokines (TGF- $\beta$, IL-4, IL-10), growth factors (IL-2, GM-CSF, G-CSF, VEGF) 
A

A 1400

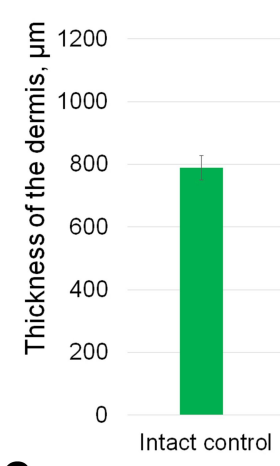

C 60

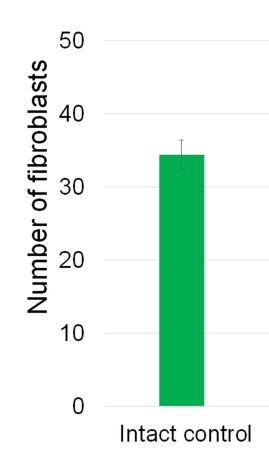

E

E.25

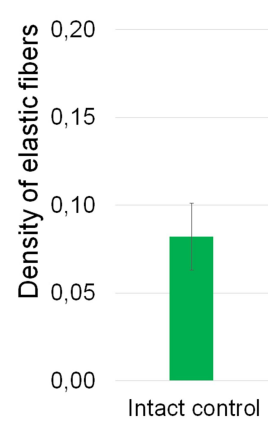

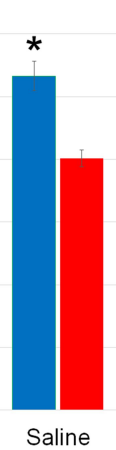
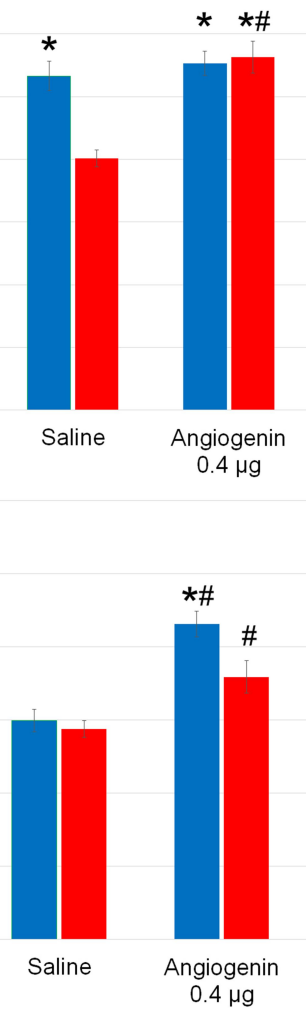
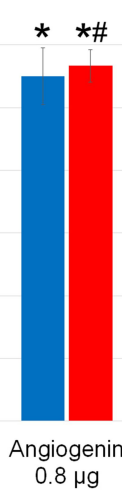

B

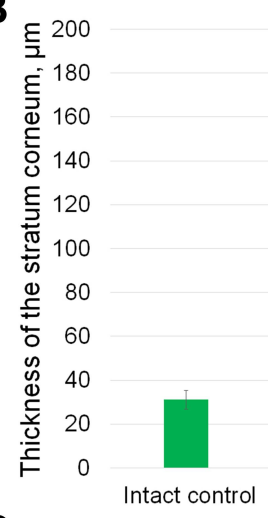

D
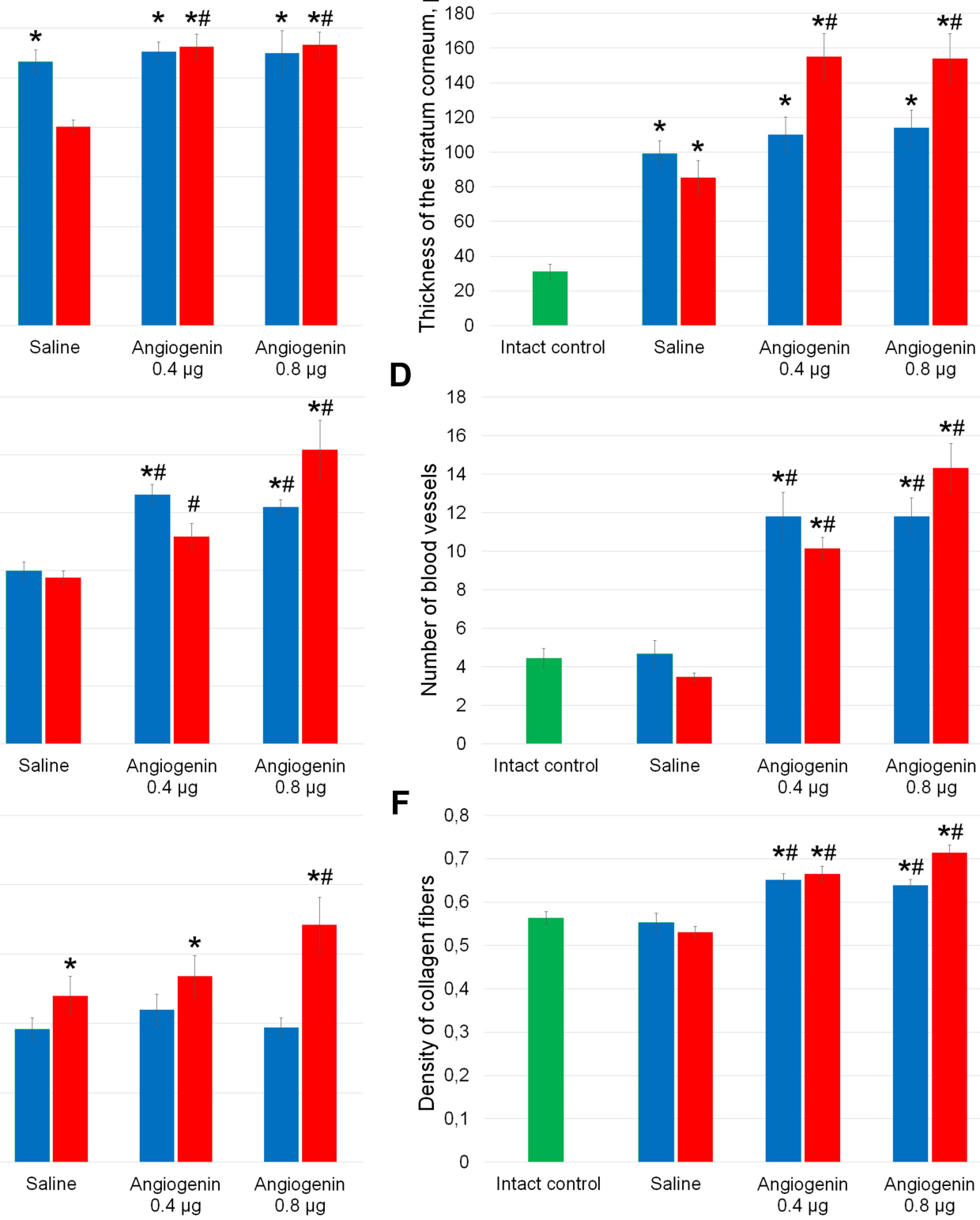

F
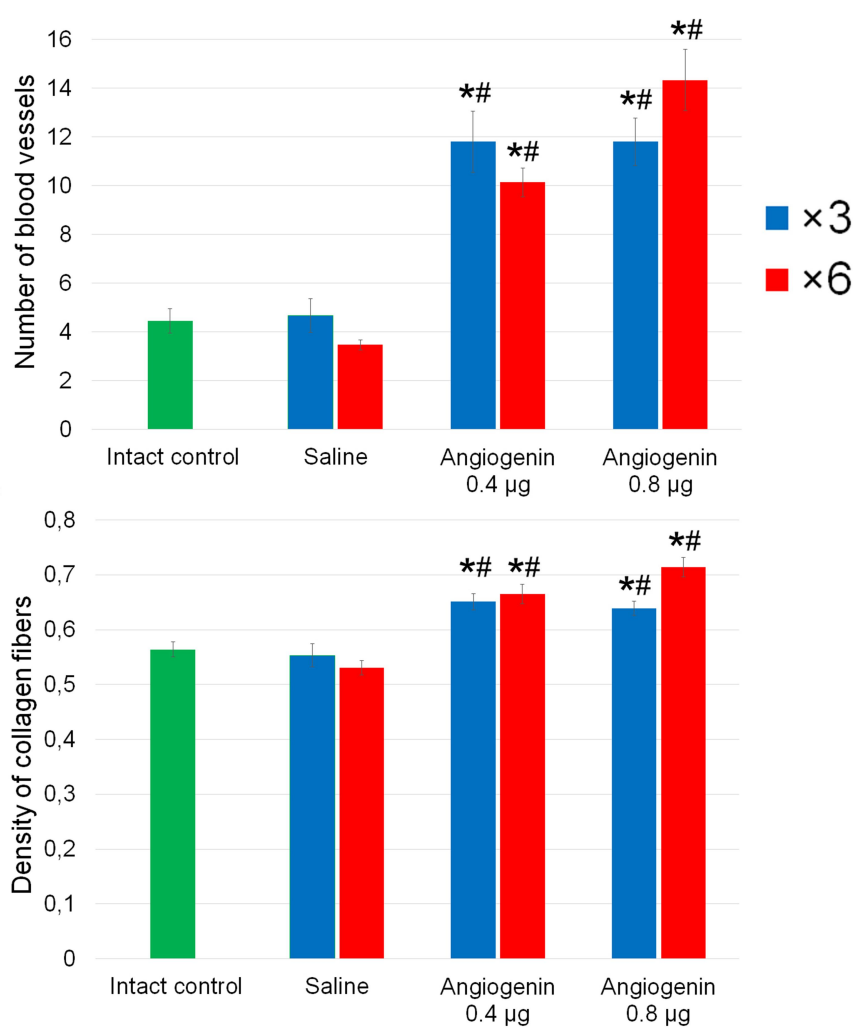

Figure 2 Quantification of pathomorphological parameters in the dermis of the intact animal and animals treated three or six times with each saline, 0.4 and $0.8 \mu g$ of angiogenin. (A) Thickness of the dermis $(\mu \mathrm{m})$; (B) thickness of the stratum corneum $(\mu \mathrm{m})$; (C) number of fibroblasts, (D) number of blood vessels; (E) density of elastic fibers; (F) density of collagen fibers in the treatment area. The method for calculating these parameters is given in the Materials and Methods section. *Significant differences from the intact controls $(p<0.05)$, ${ }^{*}$ significant differences from the saline-treated group $(p<0.05)$.

and chemokines (MCP, IL-8) by whole blood cells from healthy donors was assayed ex vivo. Angiogenin exerted a dose-dependent stimulating effect on the production of eight mediators: chemokines (MCP, a chemoattractant for monocytes/macrophages and IL-8, a chemoattractant for neutrophils/granulocytes), pro-inflammatory cytokines (IL-6, IL-1 $\beta$ and TNF- $\alpha$ ), anti-inflammatory cytokines (IL-10 and TGF- $\beta$ ) and vascular endothelial growth factor (VEGF) (Figure 4). Angiogenin did not affect the levels of
IFN- $\gamma$, IL-17, IL-18, IL-4, IL-2, GM-CSF and G-CSF significantly (as an example, data on IL-18 production are given).

\section{Discussion}

A wealth of experimental data indicate that a variety of cells produce angiogenin in the models of stressful conditions. ${ }^{11,19,40}$ Although angiogenin is commonly accepted to act predominantly in extra- and perivascular 

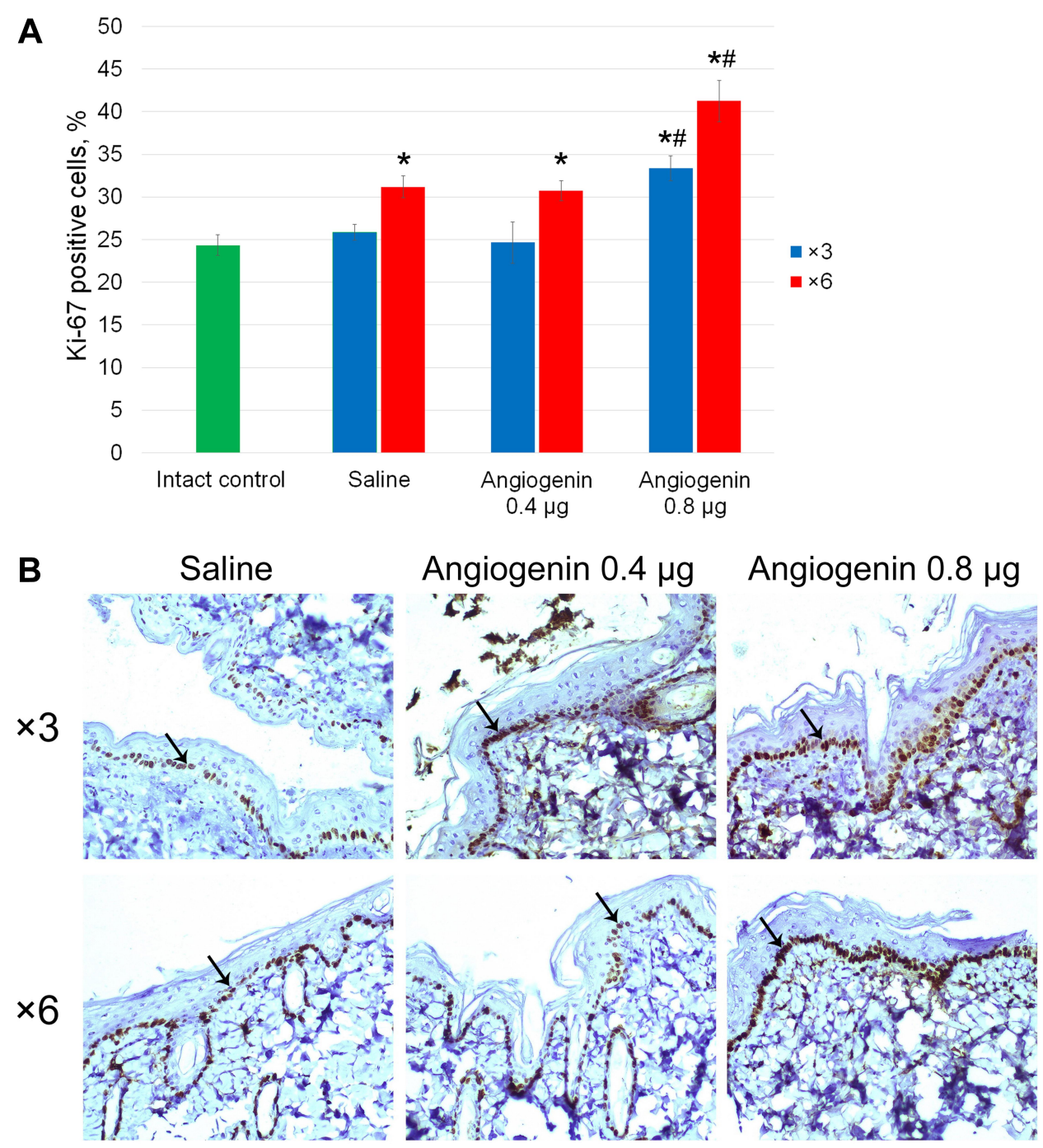

Figure 3 Proliferation of cells of the epidermis from the back of animals. (A) Ki-67-positive cells (\%). *Significant differences from the intact controls ( $p<0.05$ ), ${ }^{*}$ significant differences from the saline-treated group $(p<0.05)$. (B) Immunohistochemical staining of skin sections from animals after three and six injections of saline, 0.4 and $0.8 \mu g$ of angiogenin. Arrows point to the stained nuclei of basal cells of the epidermis. 200x magnification.

areas, circulating angiogenin is found in the normal serum at concentrations of $200-400 \mathrm{ng} / \mathrm{mL}$.

Secreted angiogenin is known to be capable of modulating the expression of genes encoding other biologically active mediators, including the factors regulating inflammatory processes. Thus, in human fibroblasts exposed to angiogenin, the expression of genes encoding cytokines and growth factors is affected: the levels of mRNA for pro-inflammatory cytokines IL-1 $\beta$, IL-6, IL-8, and TNF- $\alpha$ receptor (TNFR1) are downregulated, while those of IL-4 and IL-10 are elevated. ${ }^{11,12}$ In a rat model of endotoxin-induced uveitis, angiogenin treatment resulted in a reduced expression of IL-1 $\beta$, IL-6, IL-8, and TNF$\alpha$, while the expression of IL-4 and IL-10 was increased. ${ }^{43}$ Thus, angiogenin enhances tissue repair processes by activating of a set of anti-inflammatory cytokines.
After being treated with recombinant angiogenin, the whole blood cells were found to enhance their production of both pro- and anti-inflammatory cytokines, and this can be explained as follows.

It is possible that angiogenin, acting as a protective homeostatic factor, exerts a substantial effect on blood cells, and activation of the inflammatory process in both directions is immediately associated with its angiogenic capabilities.

It can be presumed that intradermal administration of angiogenin facilitates activation of circulating cells (lymphocytes, monocytes, neutrophils, parietal granulocytes and endothelial cells) in the dermal blood vessels. As a result, the endogenous production of a variety of proinflammatory (TNF- $\alpha$, IL-1 $\beta$, IL-6, IFN- $\gamma$, IL-17, IL-18) 

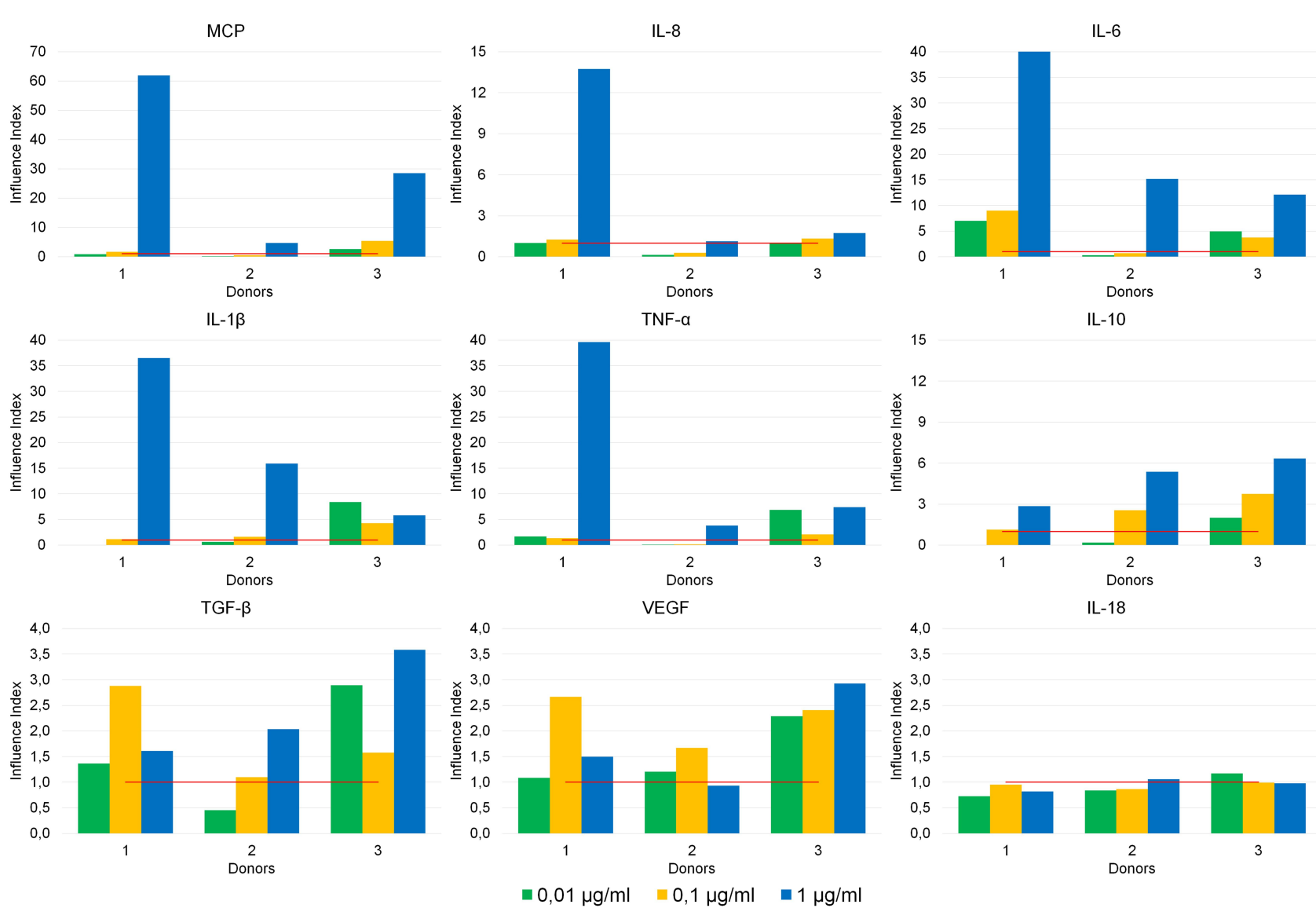

Figure 4 Effects of angiogenin at doses of $0.01,0.1$ and I $\mu \mathrm{g} / \mathrm{mL}$ on cytokine production by whole blood cells from healthy donors ( $\mathrm{n}=3$ ). The $y$-axis represents the "Influence Index" (the ratio of cytokine production by the cells exposed to angiogenin at the corresponding concentration to the basal level of cytokine production by untreated cells). The red line signifies the basal level of cytokine production (taken as "I").

and anti-inflammatory (TGF- $\beta$, IL-4, IL-10) cytokines, growth factors (IL-2, GM-CSF, G-CSF, VEGF), and chemokines (MCP, IL-8) is triggered. Chemokines (MCP, IL8) and pro-inflammatory cytokines (IL-1 $\beta$, TNF- $\alpha$ ) autoand paracrinally increase the permeability of capillaries, edema and cellular infiltration in the epidermis and in the subcutaneous area. This, in turn, facilitates the migration of activated endotheliocytes to the perivascular area and the development of a new layer of endothelial cells, which precedes the development of a new blood vessel.

IL-6 activates fibroblasts, which, in turn, start to express IL-6 and IL-8, facilitating their activated state. TGF- $\beta$ and IL-10 stimulate their growth/proliferation and subsequent differentiation, as well as the production of extracellular matrix components (collagen) and specific proteoglycans required for the transformation of the newly formed endothelial plate into a tube and its consequent remodeling into a vessel. Angiogenin, in combination with VEGF, stimulates the formation on new blood vessels. ${ }^{19,30,31}$
Thus, angiogenin functions as a trigger for a cascade of local cytokine-mediated reactions that synergistically and additively regulate the functional state of the dermis, which has been confirmed by morphological and histochemical assays of skin specimens from the injection sites. Since angiogenin affects cytokine production by blood cells in a dose-dependent manner, it can be presumed that the processes induced will be more pronounced upon increasing either the dosage $(0.8$ vs $0.4 \mu \mathrm{g})$ or the number of injections ( $n=6$ vs $n=3$ ).

\section{Conclusion}

Intracutaneous injections of angiogenin were found to stimulate collagen fiber formation and angiogenesis. This stimulation was tightly associated with an increase in the number of fibroblasts, an increased density of dermal blood vessels and an increased density of collagen fibers, as well as with the activation of the proliferation of basal cells. Angiogenin induced the production of a range of cytokines by human whole blood cells. The results 
obtained indicate a broad spectrum of actions of recombinant angiogenin during regenerative processes in the basal layer of the dermis.

\section{Acknowledgments}

The work was supported by the Ministry of Science and Higher Education of the Russian Federation via the Institute of Cytology and Genetics (state budget project No 0259-20210013) and the LLC "Angiopharm Laboratory".

\section{Disclosure}

The authors report no conflicts of interest in this work.

\section{References}

1. Goncalves KA, Silberstein L, Li S, et al. Angiogenin promotes hematopoietic regeneration by dichotomously regulating quiescence of stem and progenitor cells. Cell. 2016;166(4):894-906. doi:10.1016/j.cell.2016.06.042

2. Yu D, Cai Y, Zhou W, Sheng J, Xu Z. The potential of angiogenin as a serum biomarker for diseases: systematic review and meta-analysis. Dis Markers. 2018;2018:1-15. doi:10.1155/2018/1984718

3. Koutroubakis IE, Xidakis C, Karmiris K, Sfiridaki A, Kandidaki E, Kouroumalis EA. Serum angiogenin in inflammatory bowel disease. Dig Dis Sci. 2004;49(11-12):1758-1762. doi:10.1007/s10620-0049565-4

4. King TV, Vallee BL. Neovascularisation of the meniscus with angiogenin: an experimental study in rabbits. $J$ Bone Jt Surg - Ser B 1991;73(4):587-590. doi:10.1302/0301-620x.73b4.1712788

5. Kishimoto K, Liu S, Tsuji T, Olson KA, Hu GF. Endogenous angiogenin in endothelial cells is a general requirement for cell proliferation and angiogenesis. Oncogene. 2005;24(3):445-456. doi:10.1038/ sj.onc. 1208223

6. Hu GF, Chang SIK, Riordan JF, Vallee BL. An angiogenin-binding protein from endothelial cells. Proc Natl Acad Sci U S A. 1991;88 (6):2227-2231. doi:10.1073/pnas.88.6.2227

7. Hu GF, Strydom DJ, Fett JW, Riordan JF, Vallee BL. Actin is a binding protein for angiogenin. Proc Natl Acad Sci U S A. 1993;90 (4):1217-1221. doi:10.1073/pnas.90.4.1217

8. Hu GF, Riordan JF, Vallee BL. Angiogenin promotes invasiveness of cultured endothelial cells by stimulation of cell-associated proteolytic activities. Proc Natl Acad Sci U S A. 1994;91(25):12096-12100. doi:10.1073/pnas.91.25.12096

9. Yu W, Goncalves KA, Li S, et al. Plexin-B2 mediates physiologic and pathologic functions of angiogenin. Cell. 2017;171(4):849-864.e25. doi:10.1016/j.cell.2017.10.005

10. Sadagopan S, Veettil MV, Chakraborty S, et al. Angiogenin functionally interacts with $\mathrm{p} 53$ and regulates $\mathrm{p} 53$-mediated apoptosis and cell survival. Oncogene. 2012;31(46):4835-4847. doi:10.1038/onc.2011.648

11. Lee SH, Kim KW, Joo K, Kim JC. Angiogenin ameliorates corneal opacity and neovascularization via regulating immune response in corneal fibroblasts. BMC Ophthalmol. 2016;16(1). doi:10.1186/ s12886-016-0235-z

12. Lee SH, Kim KW, Min KM, Kim KW, Chang SI, Kim JC. Angiogenin reduces immune inflammation via inhibition of tankbinding kinase 1 expression in human corneal fibroblast cells. Mediators Inflamm. 2014;2014:1-12. doi:10.1155/2014/861435

13. Pizzo E, Sarcinelli C, Sheng J, et al. Ribonuclease/angiogenin inhibitor 1 regulates stress-induced subcellular localization of angiogenin to control growth and survival. J Cell Sci. 2013;126(18):4308-4319. doi: $10.1242 /$ jcs. 134551
14. Xia W, Fu W, Cai X, et al. Angiogenin promotes U87MG cell proliferation by activating NF- $\mathrm{\kappa B}$ signaling pathway and downregulating its binding partner FHL3. PLoS One. 2015;10(2). doi:10.1371/ journal.pone. 0116983

15. Li S, Yu W, Kishikawa H, Hu GF. Angiogenin prevents serum withdrawal-induced apoptosis of $\mathrm{P} 19$ embryonal carcinoma cells. FEBS J. 2010;277(17):3575-3587. doi:10.1111/j.1742-4658.2010.07766.x

16. Tsuji T, Sun Y, Kishimoto K, et al. Angiogenin is translocated to the nucleus of HeLa cells and is involved in ribosomal RNA transcription and cell proliferation. Cancer Res. 2005;65(4):1352-1360. doi:10.1158/0008-5472.CAN-04-2058

17. Hoang TT, Raines RT. Molecular basis for the autonomous promotion of cell proliferation by angiogenin. Nucleic Acids Res. 2017;45 (2):818-831. doi:10.1093/nar/gkw1192

18. Prehn JHM, Jirström E. Angiogenin and tRNA fragments in Parkinson's disease and neurodegeneration. Acta Pharmacol Sin. 2020;41(4):442-446. doi:10.1038/s41401-020-0375-9

19. Sheng J, Xu Z. Three decades of research on angiogenin: a review and perspective. Acta Biochim Biophys Sin (Shanghai). 2016;48 (5):399-410. doi:10.1093/abbs/gmv131

20. Moroianu J, Riordan JF. Nuclear translocation of angiogenin in proliferating endothelial cells is essential to its angiogenic activity. Proc Natl Acad Sci U S A. 1994;91(5):1677-1681. doi:10.1073/ pnas.91.5.1677

21. Wei S, Gao X, Du J, Su J, Xu Z. Angiogenin enhances cell migration by regulating stress fiber assembly and focal adhesion dynamics. PLoS One. 2011;6(12):e28797. doi:10.1371/journal.pone.0028797

22. Thomas SP, Hoang TT, Ressler VT, Raines RT. Human angiogenin is a potent cytotoxin in the absence of ribonuclease inhibitor. $R N A$. 2018;24(8):1018-1027. doi:10.1261/rna.065516.117

23. Emara MM, Ivanov P, Hickman T, et al. Angiogenin-induced tRNAderived stress-induced RNAs promote stress-induced stress granule assembly. J Biol Chem. 2010;285(14):10959-10968. doi:10.1074/jbc. M109.077560

24. Yamasaki S, Ivanov P, Hu GF, Anderson P. Angiogenin cleaves tRNA and promotes stress-induced translational repression. J Cell Biol. 2009;185(1):35-42. doi:10.1083/jcb.200811106

25. Ivanov P, Emara MM, Villen J, Gygi SP, Anderson P. Angiogenininduced tRNA fragments inhibit translation initiation. Mol Cell. 2011;43(4):613-623. doi:10.1016/j.molcel.2011.06.022

26. Ivanov P, O’Day E, Emara MM, Wagner G, Lieberman J, Anderson P. G-quadruplex structures contribute to the neuroprotective effects of angiogenin-induced tRNA fragments. Proc Natl Acad Sci U S A. 2014;111(51):18201-18206. doi:10.1073/pnas.1407361111

27. Lyons SM, Fay MM, Akiyama Y, Anderson PJ, Ivanov P. RNA biology of angiogenin: current state and perspectives. RNA Biol. 2017;14(2):171-178. doi:10.1080/15476286.2016.1272746

28. Lyons SM, Achorn C, Kedersha NL, Anderson PJ, Ivanov P. YB-1 regulates tiRNA-induced Stress Granule formation but not translational repression. Nucleic Acids Res. 2016;44(14):6949-6960. doi:10.1093/nar/gkw418

29. Deng J, Ptashkin RN, Chen Y, et al. Respiratory syncytial virus utilizes a tRNA fragment to suppress antiviral responses through a novel targeting mechanism. Mol Ther. 2015;23(10):1622-1629. doi: $10.1038 / \mathrm{mt} .2015 .124$

30. Soncin F. Angiogenin supports endothelial and fibroblast cell adhesion. Proc Natl Acad Sci U S A. 1992;89(6):2232-2236. doi:10.1073/ pnas.89.6.2232

31. Newman AC, Nakatsu MN, Chou W, Gershon PD, Hughes CCW. The requirement for fibroblasts in angiogenesis: fibroblast-derived matrix proteins are essential for endothelial cell lumen formation. Mol Biol Cell. 2011;22(20):3791-3800. doi:10.1091/mbc.E11-050393

32. Hartmann A, Kunz M, Köstlin S, et al. Hypoxia-induced up-regulation of angiogenin in human malignant melanoma. Cancer Res. 1999;59(7):1578-1583. 
33. Oikonomou KA, Kapsoritakis AN, Kapsoritaki AI, et al. Angiogenin, angiopoietin-1, angiopoietin-2, and endostatin serum levels in inflammatory bowel disease. Inflamm Bowel Dis. 2011;17(4):963-970. doi: $10.1002 /$ ibd. 21410

34. Etoh T, Shibuta K, Barnard GF, Kitano S, Mori M. Angiogenin expression in human colorectal cancer: the role of focal macrophage infiltration. Clin Cancer Res. 2000;6(9):3545-3551.

35. Tschesche H, Kopp C, Hörl WH, Hempelmann U. Inhibition of degranulation of polymorphonuclear leukocytes by angiogenin and its tryptic fragment. J Biol Chem. 1994;269(48):30274-30280. doi:10.1016/S0021-9258(18)43808-2

36. Schmaldienst S, Oberpichler A, Tschesche H, Hörl WH. Angiogenin: a novel inhibitor of neutrophil lactoferrin release during extracorporeal circulation. Kidney Blood Press Res. 2003;26(2):107-112. doi:10.1159/000070992

37. Matousek J, Soucek J, Riha J, Zankel TR, Benner SA. Immunosuppressive activity of angiogenin in comparison with bovine seminal ribonuclease and pancreatic ribonuclease. Comp Biochem Physiol. 1995;112(2):235241. doi:10.1016/0305-0491(95)00075-5

38. Srivastava M, Zurakowski D, Cheifetz P, Leichtner A, Bousvaros A. Elevated serum hepatocyte growth factor in children and young adults with inflammatory bowel disease. J Pediatr Gastroenterol Nutr. 2001;33(5):548-553. doi:10.1097/00005176-200111000-00007
39. Goryachkin AM, Sysolyatin PG, Cherdantseva LA, Potapova OV, Beklemishev AB, Baydik OD. Effect of a gel based on recombinant human angiogenin on the healing of donor palate wounds. Stomatologiia. 2019;98(1):34. doi:10.17116/stomat20199801134

40. Gulyayev AY, Lokhvitski SV, Tusupkhanov BA. Wound healing effects of man's recombined angiogenin. Med Ecol. 2010;3:9-12.

41. Purtov AA, Mamaev AL. Recombinant plasmid for expression in pichia pastoris yeast gene of chimeric protein of human angiogenin and strain of pichia pastoris yeast - producer of recombinant chimeric protein of human angiogenin. 2018. Available from: https://yandex.ru/patents/doc/ RU2658758C1 20180622. Accessed October 12, 2020.

42. Avtandilov GG. Medical Morphometry. Manual. Moscow: Medicine; 1990.

43. Park J, Kim JT, Lee SJ, Kim JC. The anti-inflammatory effects of angiogenin in an endotoxin induced uveitis in rats. Int $J$ Mol Sci. 2020;21(2). doi:10.3390/ijms21020413

\section{Publish your work in this journal}

Clinical, Cosmetic and Investigational Dermatology is an international, peer-reviewed, open access, online journal that focuses on the latest clinical and experimental research in all aspects of skin disease and cosmetic interventions. This journal is indexed on CAS.
The manuscript management system is completely online and includes a very quick and fair peer-review system, which is all easy to use. Visit http://www.dovepress.com/testimonials.php to read real quotes from published authors. 